News \& Views

\title{
A new era of China-Germany joint research exploring the climate mystery of Earth
}

\author{
Tianjun Zhou ${ }^{\mathrm{a}, \mathrm{b}, *}$, Jürg Luterbacher ${ }^{\mathrm{c}, \mathrm{d}}$, Shaohong $\mathrm{Wu}^{\mathrm{e}}$, Chao $\mathrm{Li}^{\mathrm{f}}$, Qingchen Chao ${ }^{\mathrm{g}}$, Xiao Cheng ${ }^{\mathrm{h}}$, \\ Yihong Duan ${ }^{i}$, Jian Li ${ }^{i}$, Bjorn Stevens ${ }^{f}$, Sebastian Voigt ${ }^{j}$, Yuanhang Zhang ${ }^{k}$, Xunhua Zheng ${ }^{b, l}$, Liwei Zou ${ }^{\mathrm{a}, \mathrm{b}}$ \\ a State Key Laboratory of Numerical Modeling for Atmospheric Sciences and Geophysical Fluid Dynamics (LASG), Institute of Atmospheric Physics, Chinese Academy of Sciences, \\ Beijing 100029, China \\ ${ }^{\mathrm{b}}$ Center for Excellence in Tibetan Plateau Earth Sciences, Chinese Academy of Sciences, Beijing 100101, China \\ ${ }^{\mathrm{c}}$ Department of Geography, Climatology, Climate Dynamics and Climate Change, Justus-Liebig University of Giessen, Giessen 35390, Germany \\ ${ }^{\mathrm{d}}$ Centre for International Development and Environmental Research, University of Giessen, Giessen 35390, Germany \\ e Institute of Geographic Sciences and Natural Resources Research, Chinese Academy of Sciences, Beijing 100101, China \\ ${ }^{\mathrm{f}}$ Max Planck Institute for Meteorology, Hamburg 20146, Germany \\ ${ }^{\mathrm{g}}$ Beijing Climate Center, China Meteorology Administration, Beijing 100081, China \\ ${ }^{\text {h }}$ College of Global Change and Earth System Science, Beijing Normal University, Beijing 100875, China \\ ${ }^{i}$ Chinese Academy of Meteorological Sciences, China Meteorological Administration, Beijing 100081, China \\ ${ }^{\mathrm{j}}$ Centre for European Economic Research, Mannheim 68161, Germany \\ ${ }^{\mathrm{k}}$ College of Environmental Sciences and Engineering, Peking University, Beijing 100871, China

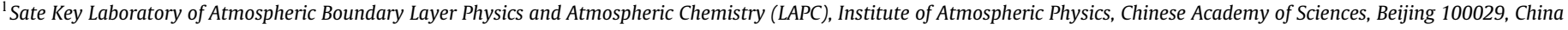

China and Germany have a long history of collaborating in the Earth sciences. One example is the collaborative work in plumbing the mysteries of climate in China. German geographer Prof. Dr. Ferdinand von Richthofen led the first scientific expedition of the Loess Plateau and Lop Nur during the 1870s. The expedition established the theory of the eolian origin of the plateau. The term "Silk Road" ("die Seidenstrasse" in German) was also coined by Prof. Ferdinand von Richthofen. The scientific expedition of northwestern China from 1927 to 1935 was led by Swedish geographer Prof. Sven Hedin, German meteorologist Prof. W. Haude, Chinese archaeologist Prof. Bingchang Xu (徐炳永), later Prof. Xianzhi Li (李宪之), and later Prof. Yanhuai Liu (刘衍淮). This was the first time meteorological and hydrological observational records were recorded in northwestern China. German Doctors of Natural Sciences have been partly responsible for pioneering Chinese modern meteorology and climate research. For example, Prof. Xianzhi Li (1904-2001) from Peking University, the pioneer of China meteorological research and education, received his doctoral degree from the University of Berlin in 1934. Prof. Jiuzhang Zhao (赵九 章) from the Chinese Academy of Sciences (1907-1968), who is the father of the Chinese satellites and the initiator of dynamical meteorology and numerical weather forecasting in China, received his doctoral Degree from the University of Berlin in 1938.

During recent decades, collaborations between the Chinese scientific community and German partners to find innovative solutions to global climate change challenges have strengthened. This

\footnotetext{
* Corresponding author at: State Key Laboratory of Numerical Modeling for Atmospheric Sciences and Geophysical Fluid Dynamics (LASG), Institute of Atmospheric Physics, Chinese Academy of Sciences, Beijing 100029, China.

E-mail address: zhoutj@lasg.iap.ac.cn (T. Zhou).
}

joint endeavor has pushed forward many research fields. For example, the Sino-German joint expedition and research of the Tibetan Plateau Glaciers has lasted from 1981 until the present [1,2]. The Pan-Third Pole Environment Change project was funded by the Chinese Academy of Sciences in 2018. Sino-German joint research on terrestrial ecosystem-atmosphere exchanges of greenhouse gases (methane, nitrous oxide and carbon dioxide) have continued since 1987 [3,4]. The more than 30 years of collaborations between the Institute of Atmospheric Physics, Chinese Academy of Sciences (IAP/CAS), and the Institute of Meteorology and Climate Research, Atmospheric Environmental Research (IMK-IFU) in this field have led to numerous fruitful outcomes. For example, a study regarding emissions of nitrous oxide $\left(\mathrm{N}_{2} \mathrm{O}\right)$, an important greenhouse gas and currently the most important individual anthropogenic ozone layer depletion matter, was published in Nature [3]. The Erwin Schrödinger Prize in 2013 was awarded to the team led by Drs. Klaus Butterbach-Bahl and Xunhuan Zheng due to this joint achievement. Collaborations between the Max Planck Institute for Meteorology (MPI-M) and IAP/CAS in climatic modeling started during the 1990s and have promoted the development of coupled climatic models in China [5,6]. In addition, in the field of climate change over the past 2000 years, many fruitful collaborations and programs between Chinese and German researchers have been established and led to important joint publications [7-14].

During this century or over the past two decades, cooperation in the climate sciences between the two countries has become increasingly important and well established. The United States (US), European Union (EU) and China account for one-half of the global Gross domestic product (GDP) according to world economic data obtained through the World Bank open database website (https://data.worldbank.org, 2018). Hence, climate and energy 
policies from the top three largest economies in the world play a key role in determining future GHG emission and will be key in attaining the goal of limiting future warming under the Paris agreement. The reduced risks of extreme climate events under the global warming targets of the Paris Agreement have been demonstrated by the scientific community [15-20]. The withdrawal of the US government from the Paris Agreement on climate change mitigations in June 2017 causes uncertainty in attaining the emission goals. It requires even closer collaboration between China and EU in developing and implementing climate policies.

The 5th Sino-German Innovation Congress was held in Beijing on February 28, 2018. This meeting marked the first time that climatic science was listed among the priorities of collaborative research between the two countries. Premier Li Keqiang called for enhanced cooperation in science and technology innovation between China and Germany in his congratulatory letter addressing the 5th Sino-German Innovation Conference. The major motivation of this paper was to promote cooperation between the two countries by embracing the opportunity of this new round of scientific and technological innovative collaboration. In this paper, after presenting a historical review of joint intergovernmental cooperation between China and Germany in the climate sciences, we summarize the existing bodies of joint research activities and propose some specific research topics for future cooperation.

The intergovernmental cooperation between China and Germany in climate sciences began during the late 1970s. The intergovernmental agreement on scientific and technological cooperation of 1978 laid the foundation for research between the two countries. Since then, China and Germany have been cooperating in the fields of science and research for 40 years. The cooperation between the two countries in research, education and innovation has particularly intensified during recent years through the Sino-German intergovernmental consultations that began in 2011. Both countries hold strategic education policy discussions to advance education cooperation, student mobility and researchers, vocational education and training. The cooperation areas include environmental protection, climate, marine and polar exploration, sustainability, urbanization, energy, mobility, health, migration, life sciences, etc. For the German Federal Ministry of Education and Research (BMBF), a budget of $\sim 20 \mathrm{M}$ Euro/a is used on the implementation of its China Strategy 2015-2020; greater than $50 \%$ of this budget is related to research on the climate, environmental and sustainability. Three years ago, the two countries established a "strategic partnership" to systematically strengthen research and innovation in cooperation.

To foster research and innovation to the mutual benefit of both countries, the BMBF developed the Strategic Framework for joint research partnership between China and Germany (i.e. China Strategy 2015-2020, BMBF). The strategic partnership between the two countries focuses on research and innovation to continue cuttingedge science to maximize the value and impact of shared capabilities and scientific expertise. Collaboration is working through the development of research programs based on the strong scientific foundation of the national climate capacity of Germany and the climate science research network of China. Education and research on global challenges call for an interdisciplinary and trans-disciplinary approach, intercultural awareness, trust and strong networking. For future cooperation with China, the China Strategy identified nine activity areas comprising thirty-five measures that should be implemented (the China Strategy 2015-2020, BMBF; https://www.bmbf.de/en/the-china-strategy-2015-2020-2345. html).

The Sino-German Center for Research Promotion (SGC) was established as a joint research funding institution based in Beijing by the Deutsche Forschungsgemeinschaft (German Research Foundation, DFG) and the National Natural Science Foundation of China
(NSFC) in 2000. The SGC is promoting scientific cooperation between China and Germany in the natural, life, engineering and management sciences. An annual open call for proposals on joint Sino-German research programs is aiming to bring together relevant and competitive researchers from Germany and China to design and conduct jointly organized research projects. In 2018, NSFC and DFG launched the first open-topic call for proposal and approved the funding of 131 proposals for joint Sino-German research projects. The funded projects have received a total of $€ 33$ million in funding over a three-year period. The active communication and cooperation between the participating researchers from the two countries will lead to high-quality research results.

Bilateral cooperation between the two countries can be implemented through existing international platforms. The Global Framework for Climate Services (GFCS) of the World Meteorology Organization (WMO) aims to enable better management of adaptation to climate change by improving the provision and use of climate information. The GFCS provides a worldwide mechanism for coordinating actions to enhance the quality, quantity and application of climate services. China and Germany can contribute to the GFCS by developing and incorporating science-based climate information and prediction into planning, policy and practice at regional and national scales.

The Intergovernmental Panel on Climate Change (IPCC) is an important cooperative body. The IPCC aims to develop sciencebased options for decisions regarding coping with climate change. It provides a scientific basis for the Paris Agreement, an accord structure within the United Nations Framework Convention on Climate Change. A total of 175 parties (174 countries and the European Union) agreed to hold the increase in global temperature below $2{ }^{\circ} \mathrm{C}$ above the preindustrial level to significantly reduce the impacts of climate change, increase the ability to adapt to the negative impacts of climate change, foster climate resilience and low carbon development, and prevent threats to food production. The Paris Agreement also results in financial expenditures consistent with a pathway towards development with low greenhouse gas emissions and climate-resilience. For international climate policy, a stronger Sino-German cooperation in research on climate, impacts, renewables, mitigation, adaptation and policy instruments (carbon pricing) is an important signal for future collaboration and the worldwide community.

Another cooperative body is the World Climate Research Programme (WCRP). To facilitate the analysis and prediction of the Earth's system change for use in a range of practical applications of direct relevance, benefit and value to society, the WCRP has established the project of Grand Challenges (GCs), identifying high-priority research fields for the next decade that need international coordination. The specific barriers preventing progress in critical areas of climate sciences are highlighted. The GCs were developed by the Joint Scientific Committee, WCRP sponsors, stakeholders and scientists. China and Germany have provided significant financial support to the WCRP. For example, China is now hosting the International CLIVAR Global Project Office in Qingdao and Germany is hosting the SPARC International Project Office in Oberpfaffenhofen. Both are helpful platforms for cooperation. The GCs have provided a useful reference for the cooperation of the two countries in research of the climate sciences.

In addition to the international project bodies, sectorial bilateral cooperation plays an essential role. For example, the MPI-M and the Chinese Academy of Meteorology Sciences (CAMS), China Meteorology Administration (CMA) signed a Memorandum of Agreement in 2017 for cooperative investigations of high-resolution climate modeling which is the most important basis to address the GCs. CAMS, supported by both the CMA and the Ministry of Science and Technology (MOST) of China, is a comprehensive research institution attached to the CMA. CAMS is now leading 
the SCMREX (Southern China Monsoon Rainfall Experiment), which is a WMO/WWRP Research and Development Project [21]. The comprehensive field campaign data collected by SCMREX helps to better understand the development of the heavy-rain-producing systems in Southern China during the pre-summer rainy season and the processes governing convective initiation development. The MPI-M in Hamburg has sought to understand Earth's climate system, using its principal tool, i.e. comprehensive Earth System modeling. MPI-M is now leading the High Definition Clouds and Precipitation for advancing Climate Prediction $\left(\mathrm{HD}(\mathrm{CP})^{2}\right)$ project in Germany, which is a BMBF-funded German-wide research initiative to improve our understanding of cloud and precipitation processes and their implications for climate prediction. The $\mathrm{HD}(\mathrm{CP})^{2}$ provides a unique tool to directly simulate clouds and precipitation over very diverse regions and addresses cloud and precipitation processes that constitute among the largest uncertainties in current weather and climate prediction models. The cooperation of the MPI-M with CAMS, including the involvement of some partner institutes and universities such as the IAP/CAS will advance our understanding of storm-internal processes (cloud precipitation microphysics and dynamics) and promote the field of high-resolution modeling. A joint workshop on multiscale modeling of atmospheric processes was organized in Guangzhou in March 2018. Researchers from the MPI, DWD, CAMS, and IAP extensively discussed multi-scale modeling and associated field observation as well as further cooperation in high-resolution (at $\sim 2-\mathrm{km}$ scale) global simulation.

Based on the strategic framework for joint research partnership between China and Germany, sectorial bilateral cooperation agreements, fruitful discussions of scientists from both countries during the 5th Sino-German Innovation Conference, memorandum of interest signed by the two countries, and high-priority research fields proposed by the international climate science community, the following fields are recommended for future joint China-Germany climate science and technology collaboration.

First, basic studies regarding climate change including:

(1) High-resolution simulation and cooperative observation of the high impact weather over the global monsoon region. Studies would include experimental design and scheme for multiscale atmospheric modeling, debugging and optimizing the German ultrahigh numerical model ICON using the Chinese super computer system, conducting the convectionpermitted simulation of the global climate, conducting the three-dimensional and high-resolution field observation at the same scale as modeling, utilizing multiple sources of data to evaluate and improve model simulation, and based on model results show the evolution of highly influential weather within monsoon regions (particularly the Asian monsoon region) during both current and future times.

(2) Three pole co-observation: Contrast and correlation of tripolar variation, Polar sea ice change mechanism, and Ice shelves interacting with the ocean. Studies would establish unattended observational systems at three poles to observe key elements of the cryosphere such as snow, sea ice, glaciers, vegetation, permafrost, lakes, oceans and the atmosphere, thus realizing long-term observations at three poles; study the ice material balance line and the variation in hydrological characteristics at the three poles, as well as their response and feedback to climate change; understand the remote correlation and coordinative mechanism among the three poles to study the effect mechanism of interglacial waterways, melting pools and interglacial lakes on sea ice and show the processes and mechanisms of the atmosphere-ocean-sea ice interaction that control their changes; and carry out research of the interaction between the ice shelf and ocean, including study of the influence from ocean circulation, interglacial lakes and other processes on ice shelf stability and the process of melting and refreezing at the bottom of the ice shelf.

Second, impacts of climate change on sensitive sectors including:

(1) Impacts of climate change and extreme events on key sensitive sectors and the further impacting attribution. The impact magnitude of climate change and extreme events on key sensitive sectors, including agriculture, water resources, natural ecosystems, biodiversity, human health, tourism and infrastructure would be studied. Identifying the contribution rate of climate change and extreme events on the spatial-temporal variation in the aforementioned sectors would also be a priority.

(2) Regional air pollution prevention under climate change. Studies would include long-term change behavior in air components and atmospheric free radical chemistry and atmospheric oxidation processes under climate change; internal correlation mechanism between air pollution and climate change and atmospheric environmental carrying capacity; and an air pollution prevention strategy coupling human health and climate effects.

(3) Impacts of changes in Arctic sea ice on mid-latitude and global climate and impact of Arctic sea retreat on haze. Studies would include impacts of changes in Arctic sea ice on the dynamic processes of the atmosphere and ocean at a large scale, the exchange of momentum, energy and mass between the mid-latitude regions and the Arctic, and the process and mechanism of mid-latitude and global climate; quantifying the interaction of atmosphere-clouds-aerosols and the feedback mechanisms of atmospheric temperature changes in Arctic regions and their effects on Arctic sea ice retreat; predicting seasonal air pollution (haze) in the Arctic; and assessing the impacts of Arctic sea retreat on air heavy pollution during winter in China.

Third, adaptation to climate change/extreme events including:

(1) Key technologies for adaptation to climate change and extreme events. Studies would include developing a technology inventory for adaptation to climate change in different sensitive sectors, assessing regional applicability and economic availability of the adaptation of the technologies; establishing indicator systems of adaptation to climate change in different sensitive sectors and measurement methods of regional climate change adaptation; and further proposing technological approaches for identifying the effectiveness of adaptation to climate change.

(2) Climate change risk projection and sustainable transformation. Studies would include projection of the evolutionary trend of extreme events (e.g., heatwaves, floods and droughts) over the next $10 \sim 30$ years and identifying the critical thresholds of climate change impacts and risks; quantitatively assessing the socioeconomic impacts and risks of climate change and extreme events and the project evolution trend of the water-grain-energy-ecology-related security situation and systemic risks over the next $10 \sim 30$ years, estimating risks of construction and operation of major projects; establishing a comprehensive assessment model by coupling global change economics, climate change impacts and sustainable transformation models to find a sustainable development pathway through enhancing climate resilience. 
In summary, close collaboration between China and Germany/ EU in the climate sciences is believed to enable the successful implementation of international projects sponsored by the WMO, the WCRP and the IPCC. The Sino-German Innovation Conference promoted and will continue to promote face-to-face discussions between Chinese and German scientists regarding climate science cooperation. The proposed research topics outlined here will hopefully form the basis of bilateral cooperation in research of climate science and technologies. Cooperation will provide opportunities to both countries.

\section{Conflict of interest}

The authors declare that they have no conflict of interest.

\section{Acknowledgments}

This work was jointly supported by the Strategic Priority Research Programme of Chinese Academy of Sciences (XDA20060102) and the International Partnership Program of Chinese Academy of Sciences (134111KYSB20160031).

\section{References}

[1] Huintjes E, Sauter T, Schröter B, et al. Evaluation of a coupled snow and energy balance model for Zhadang Glacier, Tibetan Plateau, using glaciological measurements and time-Lapse photography. Arct Antarct Alpine Res 2015;47:573-90.

[2] Zhu M, Yao T, Yang W, et al. Energy- and mass-balance comparison between Zhadang and Parlung No. 4 glaciers on the Tibetan Plateau. J Glaciol 2015;61:595-607.

[3] Wolf B, Zheng X, Brüggemann N, et al. Grazing-induced reduction of natural nitrous oxide release from continental steppe. Nature 2010;464:881-4.

[4] Chen W, Wolf B, Zheng X, et al. Annual methane uptake by temperate semiarid steppes as regulated by stocking rates, aboveground plant biomass and topsoil air permeability. Glob Change Biol 2011;17:2803-16.

[5] Zhang XH, Oberhuber JM, Bacher A, et al. Interpretation of interbasin exchange in an isopycnal ocean model. Clim Dyn 1998;14:725-40.

[6] Hu ZZ, Latif M, Roeckner E, et al. Intensified Asian summer monsoon and its variability in a coupled model forced by increasing greenhouse gas concentrations. Geophys Res Lett 2000;27:2681-4.

[7] Ge QS, Zheng JY, Hao ZX, et al. Temperature variation through 2000 years in China: An uncertainty analysis of reconstruction and regional difference. Geophys Res Lett 2010;37:L03703.
[8] Man W, Zhou T, Jungclaus JH. Simulation of the East Asian summer monsoon during the last millennium with the MPI Earth System Model. J Clim 2012;25:7852-66.

[9] Man W, Zhou T, Jungclaus JH. Effects of large volcanic eruptions on global summer climate and East Asian monsoon changes during the last millennium: analysis of MPI-ESM simulations. J Clim 2014;27:7394-409.

[10] Luterbacher J, Werner JP, Smerdon JE, et al. European summer temperatures since Roman times. Environ Res Lett 2016;11:024001.

[11] Wang J, Yang B, Ljungqvist FC, et al. Internal and external forcing of multidecadal Atlantic climate variability over the past 1200 years. Nat Geosci 2017;10:512-7.

[12] Duan J, Esper J, Büntgen U, et al. Weakening of annual temperature cycle over the Tibetan Plateau since the 1870s. Nat Commun 2017;8:14008.

[13] Zhang H, Werner JP, García-Bustamante E, et al. East Asian warm season temperature variations over the past two millennia. Nat Sci Rep 2018;8:7702.

[14] Wu B, Zhou T, Li C, et al. Improved decadal prediction of Northern-Hemisphere summer land temperature. Clim Dyn 2019;53:1357-69.

[15] Nangombe S, Zhou T, Zhang W, et al. Record-breaking climate extremes in Africa under stabilized $1.5^{\circ} \mathrm{C}$ and $2^{\circ} \mathrm{C}$ global warming scenarios. Nat Clim Change 2018;8:375-80.

[16] Zhang W, Zhou T, Zou L, et al. Reduced exposure to extreme precipitation from $0.5^{\circ} \mathrm{C}$ less warming in global land monsoon regions. Nat Comm 2018;9:3153.

[17] Suarez-Gutierrez L, Li C, Muller W, et al. Internal variability in European summer temperatures at $1.5^{\circ} \mathrm{C}$ and $2^{\circ} \mathrm{C}$ of global warming. Environ Res Lett 2018;13:064026.

[18] Li D, Zhou T, Zou L, et al. Extreme high-temperature events over East Asia in $1.5^{\circ} \mathrm{C}$ and $2^{\circ} \mathrm{C}$ warmer futures: analysis of NCAR CESM low-warming experiments. Geophys Res Lett 2018;45:1541-50.

[19] Zhou T, Ren L, Liu H, et al. Impact of $1.5^{\circ} \mathrm{C}$ and $2.0^{\circ} \mathrm{C}$ global warming on aircraft takeoff performance in China. Sci Bull 2018;63:700-7.

[20] Wang F, Ge Q, Chen D, et al. An updated estimate of global and regional climate responses to national-committed emission reductions under the Paris Agreement. Geogr Ann Ser A Phys Geogr 2018;100:240-53.

[21] Luo Y, Zhang R, Wan Q et al. The Southern China monsoon rainfall experiment (SCMREX). Bull Am Meteorol Soc 2017;98:999-1014.

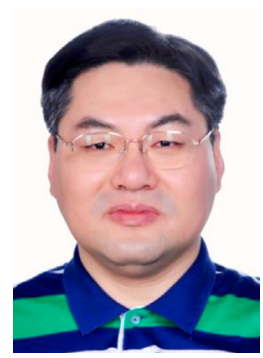

Tianjun Zhou is a professor of Institute of Atmospheric Physics, Chinese Academy of Sciences. His personal research focuses on coupled atmosphere-ocean modelling, climate dynamics, climate change and variability, with particular emphasis on East Asia and the monsoons. 